\title{
RANCANG BANGUN "TELEGRAM BOT API" UNTUK LAYANAN SISTEM INFORMASI AKADEMIK DI UNWAHA MENGGUNAKAN METODE LONG POLLING
}

\author{
Fika Ridaul Maulayya, Muhyiddin Zainul Arifin, Tholib Hariono
}

Fakultas Teknologi Informasi Universita KH. A. Wahab Hasbullah

Correspondence Author: ridaulmaulayya@gmail.com

\begin{tabular}{|c|c|}
\hline Info Artikel : & ABSTRAK \\
\hline $\begin{array}{l}\text { Keywords: } \\
\text { Academic } \\
\text { Information } \\
\text { Systems, Telegram } \\
\text { BOT, Long Polling } \\
\text { Method }\end{array}$ & $\begin{array}{l}\text { Today, the information system needs are not limited to the } \\
\text { importance of the information, but the ease and speed of getting the } \\
\text { information is a priority that must be fulfillied. This makes many instant } \\
\text { messaging applications appear. One of them is a telegram that has features } \\
\text { the BOT telegram API, which is a special protocol for connecting } \\
\text { information from a system to a user through Instant Messaging. } \\
\text { In this research, the researcher used BOT features of the instant } \\
\text { messaging application for Academic Information system at KH. A Wahab } \\
\text { Hasbullah University, includes of data KHS, KRS, information dissemination, } \\
\text { transcripts of score, lecture schedules and others. This research used the } \\
\text { Long Polling method. This method is used becauce it can be implemented on } \\
\text { a local PC server that is owned by KH. A Wahab Hasbullah University. This } \\
\text { telegram BOT has a better speed compared to conventional web versions, } \\
\text { this speed testing is done in two steps. First, Use of a BOT of this Telegram } \\
\text { has better speeds compared to conventional web version, this speed test is } \\
\text { carried out by two steps, 1) the result of BOT telegram using } 512 \mathrm{~kb} \\
\text { Bandwidth with average is } 2.98 \text { seconds, conventional web is } 5.39 \text { seconds; } \\
\text { 2) the result of BOT Telegram using } 1 \text { MB bandwidth with average is } 2.44 \\
\text { seconds, conventional web is } 3.15 \text { seconds. }\end{array}$ \\
\hline
\end{tabular}

INTISARI

Kata Kunci :

Sistem Informasi

Akademik, BOT

Telegram, Metode

Long Polling
Dewasa ini kebutuhan sistem informasi tidak terbatas pentingnya informasi tersebut, namun kemudahan dan kecepatan untuk mendapatkan info tersebut menjadi prioritas yang harus di penuhi. Hal ini membuat banyaknya bermunculan aplikasi pesan instan salah satunya adalah Telegram yang memeliliki fitur BOT Telegram API, yaitu protokol khusus untuk menghubungkan informasi dari suatu sistem ke pengguna melalui pesan instan.

Pada penelitian ini penulis memanfaatkan fitur BOT dari aplikasi pesan instan Telegram untuk layanan Sistem Informasi Akademik di UNWAHA meliputi data KHS, KRS, Penyebaran Informasi, Transkip Nilai, Jadwal Perkuliahan, dan lain-lain. Penelitian ini menggunakan metode Long Polling, metode ini digunakan karena mampu diimplementasikan di lokal PC server yang dimiliki UNWAHA. Penggunaan BOT Telegram ini memiliki kecepatan yang lebih baik dibandingkan dengan versi web konvensional, pengujian kecepatan ini dilakukan dengan 2 langkah, pertama dengan bandwidth $512 \mathrm{~Kb}$ diperoleh hasil BOT Telegram dengan rata-rata 2.98 Detik, Web Konvensional 5.39 Detik. Dan menggunakan bandwidth 1 MB diperoleh hasil BOT Telegram dengan rata-rata 2.44 Detik, Web Konvensional 3.15 Detik. 


\section{PENDAHULUAN}

Sistem informasi akademik merupakan suatu alat untuk menyajikan informasi dengan cara sedemikian rupa sehingga bermanfaat bagi menurut Kertahadi (Hartati 2015, h.2). Dengan dukungan sistem informasi akademik yang baik dapat dimungkinkan mahasiswa lebih mudah mendapatkan informasi akademik seperti melihat jadwal UTS, jadwal UAS, data KHS, KRS dan jadwal perkuliahan. Telegram mengkalim sebagai aplikasi pesan massal tercepat dan teraman yang berada dipasar. Selain itu Telegram juga menyediakan wadah bagi pengembang yang ingin memanfaatkan Open Api dan Protocol yang disediakan melalui pengembang Telegram Bot yang didokumentasikan pada web resminya. Penggunaan media sosial yang berkembang sangat cepat dan tinggi, membuat banyaknya bermunculan aplikasi pesan instan seperti Facebook Messager, Line, Slack dan Telegram (Hatta Nur Rochim, 2016). Sebagai sarana layanan akademik maka dimungkinkan sistem informasi akademik (SIAKAD) akan membuat sebuah Telegram Bot Api yang mana dapat memberikan kemudahan dan kecepatan dalam mendapatkan informasi tentang akademik tanpa harus masuk ke web browser kemudian mengetikkan alamat sistem informasi akademik (SIAKAD) dan memasukkan username dan password. Dengan menggunakan Telegram Bot Api kita hanya perlu membuka aplikasi Telegram dan dan memasukkan NIM (nomor induk mahasiswa) ke akun Telegram Bot Api dan kemudian Telegram Bot Api akan melakukan pengecekan apakah NIM (nomor induk mahasiswa) tersebut sudah terdaftar di Telegram Bot Api atau belum dan jika sudah terdaftar maka akan dilakukan untuk autentikasi masuk ke sistem informasi akademik (SIAKAD).

\section{METODE PENELITIAN}

2.1. Analisis Sistem

Analisis kebutuhan sistem digunakan untuk mengetahui kebutuhan-kebutuhan dalam merealisasikan pembuatan aplikasi BOT Telegram. Analisis kebutuhan dibagi menjadi dua jenis, yaitu kebutuhan fungsional dan kebutuhan non fungsional :

1. Kebutuhan Fungsional

Kebutuhan fungsional aplikasi BOT Telegram yang terintegrasi dengan sistem informasi akademik di UNWAHA, terdiri dari proses kerja dalam sistem. Adapun kebutuhan fungsional dari aplikasi BOT Telegram adalah:

Aplikasi ini mempunya beberapa menu diantaranya, daftar, keluar, lihat data KRS, KHS, cetak data KRS, KHS, lihat jadwal akademik, pengumuman, profil mahasiswa, dan transkip nilai mahasiswa.

2. Kebutuhan Non Fungsional

Kebutuhan non fungsional adalah kebutuhan menitikberatkan pada properti prilaku yang dimiliki oleh sistem. Adapun analisa kebutuhan non fungsional dari aplikasi BOT Telegram adalah:

- Kebutuhan Perangkat Keras

Perangkat

RAM

Layar

- Kebutuhan Perangkat Lunak

Sistem operasi PC

Sistem operasi Smartphone

Tools Editor
: Smartphone Android

: Minimum 512MB

: LCD Touchscreen

: Mac OSX

: Android 5.1 Lollipop

: VIM, TMUX, PhpStorm

\subsection{Model Waterfall}

Penelitian ini akan melakukan tahapan-tahapan System Development Life Cycle (SDLC) dengan model waterfall seperti pada Gambar 1. 


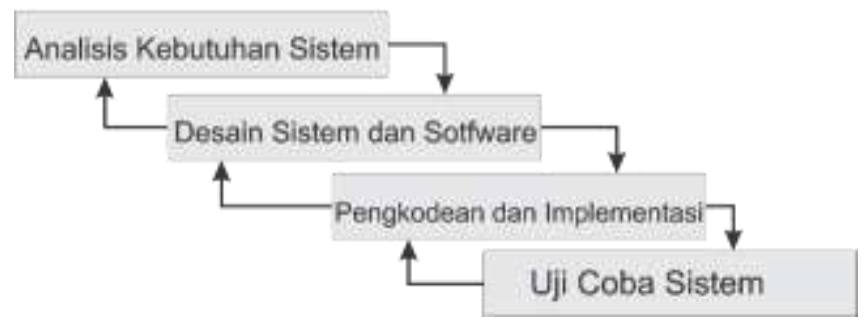

Gambar 1. Model Waterfall

Metode waterfall (air terjun) adalah proses pembuatan situs web secara terstruktur dan berurutan. Model air terjun di sebut juga model sekuensial linier (sequential linear) atau alur hidup klasik yang meliputi: analisis kebutuhan sistem, desain sistem dan software, pengkodean dan implementasi dan uji coba sistem (Rosa \& Shalahuddin,2013). Alur proses model air (waterfall) terjun.

1. Analisa Kebutuhan Sistem

Pada tahapan ini dilakukan proses analisis kebutuhan sistem, di mana menjabarkan seluruh kebutuhan sistem dan membuat spesifikasi lengkap tentang isi sistem. Dalam tahap ini segala kebutuhan sistem dijabarkan dengan lengkap, mulai dari perangkat lunak dan perangkat keras yang dibutuhkan untuk pengembangan sistem.

2. Desain Sistem dan Software

Pada tahap ini berfokus pada perancangan sistem. Pada tahap ini terdapat dua level yaitu: desain level tinggi (arsitektur sistem) dan desain level rendah. Desain level tinggi meliputi perancangan struktur data, model perangkat lunak, dan mendefinisikan prosedurprosedur yang diperlukan. Sedangkan desain level rendah yaitu merancang tampilan user interface yang meliputi tata layout aplikasi, navigasi dan lain-lain.

3. Pengkodean dan Implementasi

Pada tahap ini dilakukan proses penerjemahaan desain kedalam bahasa yang di mengerti komputer. bahasa-bahasa tersebut diterjemahkan dalam bahasa pemrograman agar dapat dimengerti komputer.

Dalam penelitian ini, peneliti menggunakan bahasa pemrograman PHP Hypertext Preprocessor (PHP) untuk menerjemahkan kedalam bahasa komputer dan dilakukan oleh seorang programmer. penerjemahan mengacu pada perancangan yang telah dibuat pada tahap desain.

4. Pengujian Sistem

Setelah tahapan-tahapan sebelumnya selesai dilakukan, maka tahapan selanjutnya adalah proses pengujian sistem. Pengujian sistem diperlukan untuk meminimalisir adanya kesalahan pada sistem. Pegujian dilakukan dengan menggunakan pengujian BlackBox Testing .

Pengujian Black-Box Testing bertujuan untuk mengetahui fungsi dari sistem, apakah sistem telah berjalan sesuai fungsinya atau belum. Teknik pengujian black-box pada penelitian ini menggunakan teknik boundry values analysis (BVA) yaitu suatu teknik pengujian perangkat lunak di mana tes dirancang untuk mencakup perwakilan dari nilainilai batas (Liana, 2015). Proses pengujian dengan menggunakan Black-Box yaitu dengan cara menguji satu persatu inputan pada sistem. Hasil dari pengujian digunakan sebagai bahan evaluasi pada sistem.

\subsection{Pemodelan Use Case Diagaram}

Pemodelan Use case aplikasi BOT Telegram Universitas KH. A. Wahab Hasbullah, digunakan untuk mendeskripsikan aktor dan aktivitas yang dilakukan oleh aktor. Deskripsi aktor dan aktivitas yang dilakukan oleh aktor akan dijabarkan pada tabel 1. 
Tabel 1. Use Case Diagram Aktor

\begin{tabular}{|c|l|}
\hline \multicolumn{1}{|c|}{ Aktor } & \multicolumn{1}{c|}{ Keterangan } \\
\hline Mahasiswa & $\begin{array}{l}\text { Setiap user dapat melihat dan mencetak informasi yang ada di dalam } \\
\text { sistem informasi akademik setelah berhasil mendaftar di BOT } \\
\text { telegram. }\end{array}$ \\
\hline
\end{tabular}

Untuk tugas dan fungsi setiap aktor dalam sistem, dapat dilihat pada Gambar 4

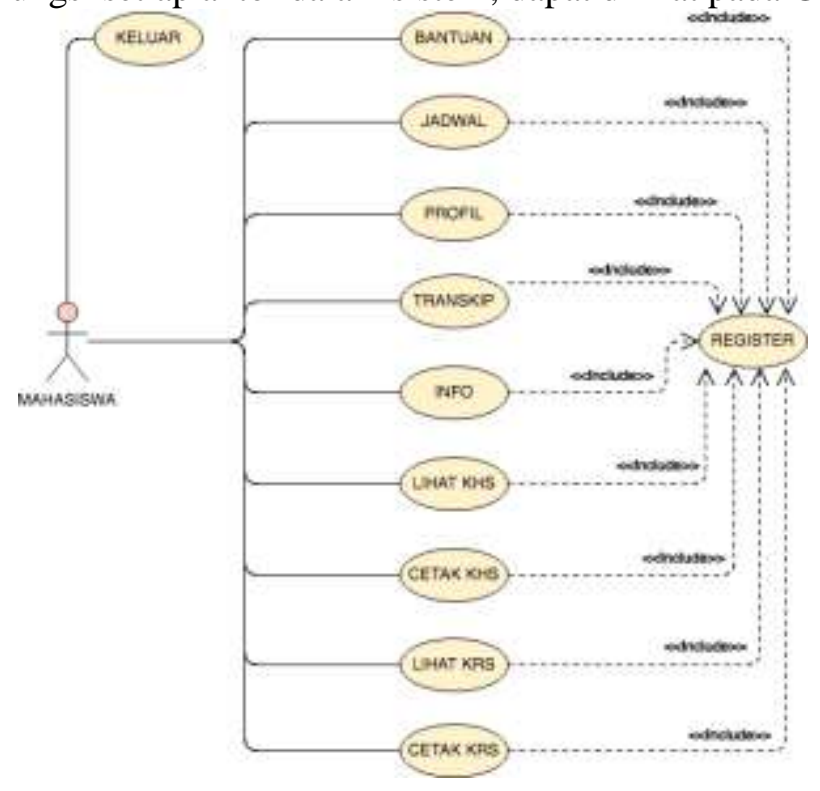

Gambar 2. Use Case Diagram BOT Telegram

\subsection{Activity Diagram}

Activity diagram berikut menggambarkan bagaimana mahasiswa melakukan request terhadap informasi data akademik melalui BOT Telegram.

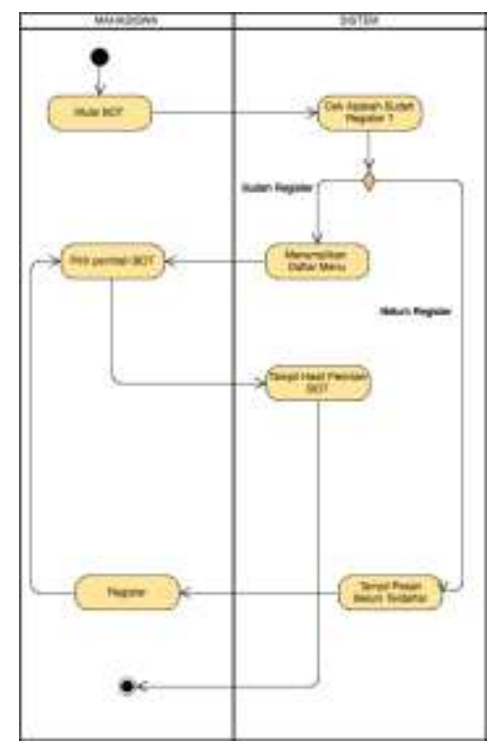

Gambar 3. Activity Diagram BOT Telegram 


\subsection{Relasi Database}

Desain relasi antar tabel yang digunakan pada aplikasi BOT Telegram dapat dilihat pada Gambar 6.

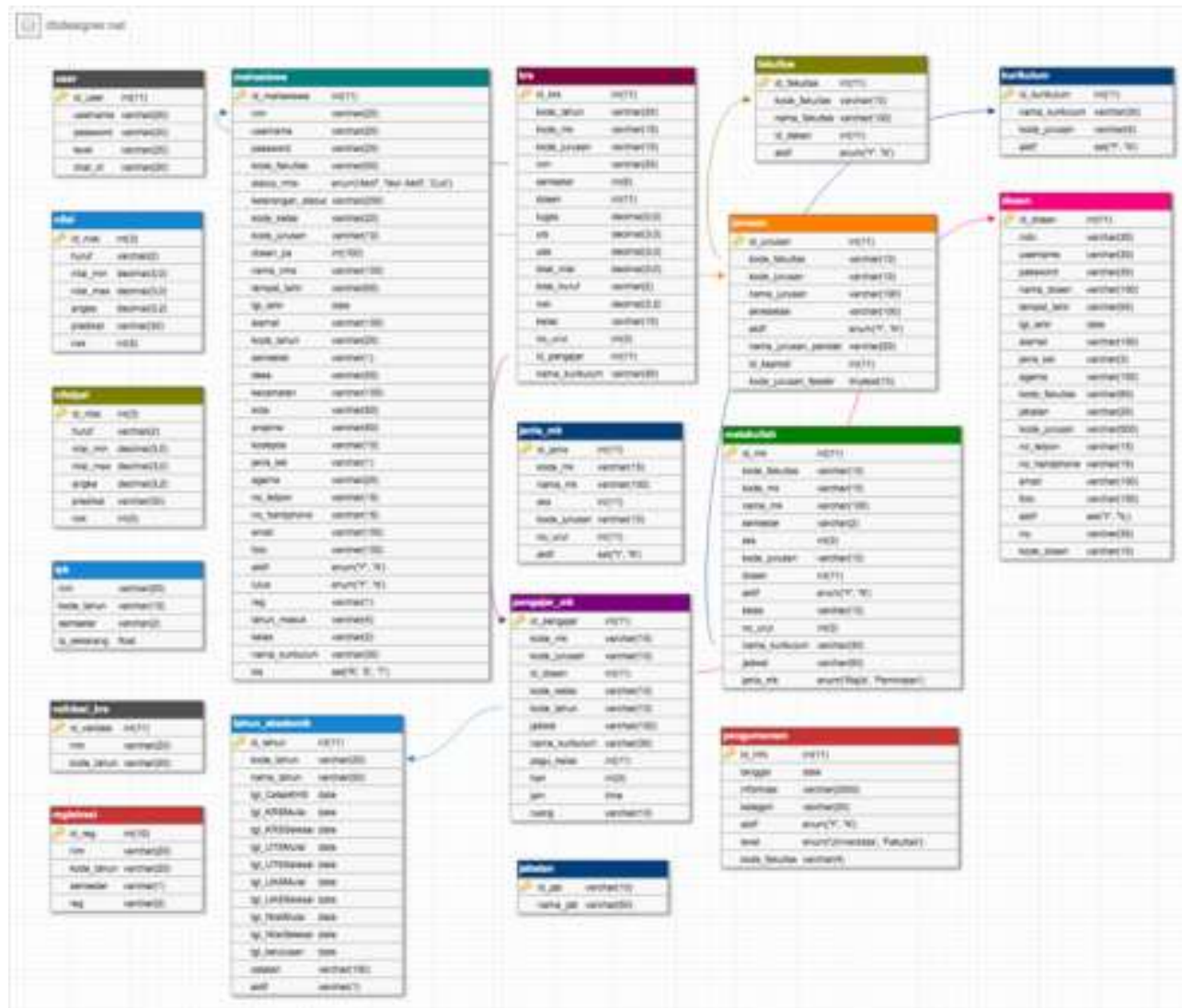

Gambar 4. Relasi Database Sistem Informasi Akademik

Database pada aplikasi BOT Telegram terdiri dari 15 tabel diantaranya adalah:

1. Tabel User: merupakan tabel yang digunakan untuk masuk ke sistem.

2. Tabel mahasiswa dan tabel krs: satu mahasiswa dapat mempunyai banyak krs. Artinya setiap mahasiswa dapat menambah data krs berdasarkan tahun akademik.

5. Tabel fakultas dan tabel jurusan: satu fakultas mempunyai banyak jurusan. Artinya setiap 1 fakultas dapat menambah banyak jurusan.

6. Tabel krs dan tabel pengajar mk: setiap data krs mempunyai data pengajar. Artinya pada tabel krs setiap data mempunya tenaga pengajar masing-masing.

7. Tabel dosen dan tabel pengajar mk: tabel pengajar mk merupakan tabel yang berisi data pengajar mata kuliah beserta jadwalnya.

8. Tabel pengajar mk dan tabel tahun akademik: karena tabel pengajar mk merupakan tabel yang berisi jadwal akademik maka tahun akademik mempunyai relasi denga pengajar mk sebagai kode tahunnya.

9. Tabel kurikulum dan tabel matakuliah: setiap matakuliah mempunya kurikulum sendiri, Artinya setiap kurikulum dapat menyimpan banyak matakuliah.

\subsection{Perancangan Interface Aplikasi}

Perancangan Interface/Antaramuka adalah sebuah gambaran yang digunakan untuk memperjelas aplikasi ini seperti apa yang akan dibuat, bagaimana aplikasi tersebut bekerja, apa saja fitur-fitur yang ada dalam aplikasi tersebut. 


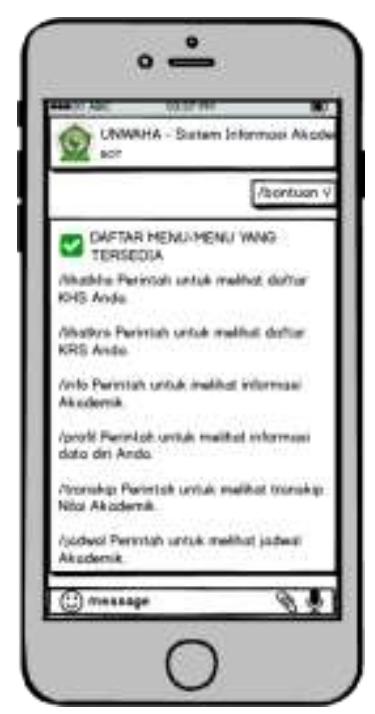

Gambar 5. Rancangan Daftar Menu Aplikasi BOT Telegram

\section{HASIL DAN PEMBAHASAN}

Dibagian ini peneliti memebahas beberapa hal yang terkait dari pembuatan aplikasi BOT Telegram, yaitu meliputi antarmuka (interface) dan hasil pengujian.

\subsection{Antarmuka (interface)}

Dalam aplikasi BOT telegram ini terdapat beberapa layout yang berbeda yaitu sebagai berikut.

1. Tampilan awal BOT Telegram

Perintah start adalah perintah awal yang ditampilkan ketika kita baru saja membuka aplikasi. Dalam hal ini user dapat menekan tombol start untuk memulai menggunakan aplikasi.

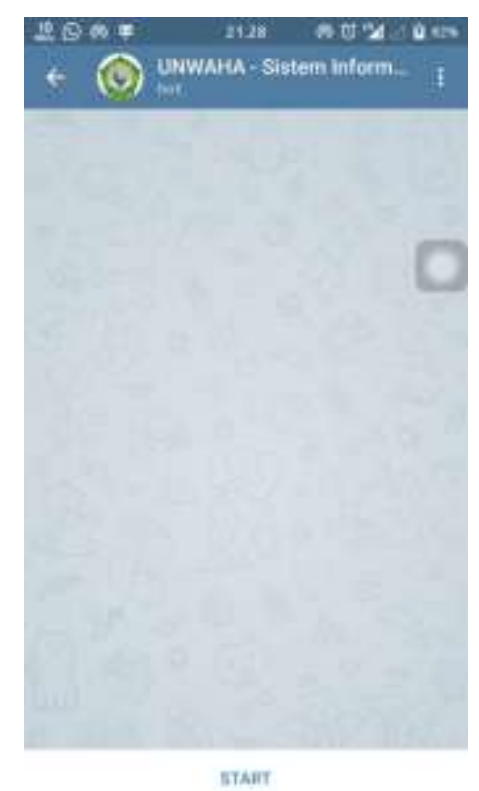

Gambar 6. Tampilan Awal Aplikasi BOT Telegram 
2. Tampilan Menu Bantuan

Perintah bantuan setelah mendaftar adalah perintah yang akan menampilkan menu-menu yang ada di aplikasi, dengan cara user harus mendaftar terlebih dahulu.

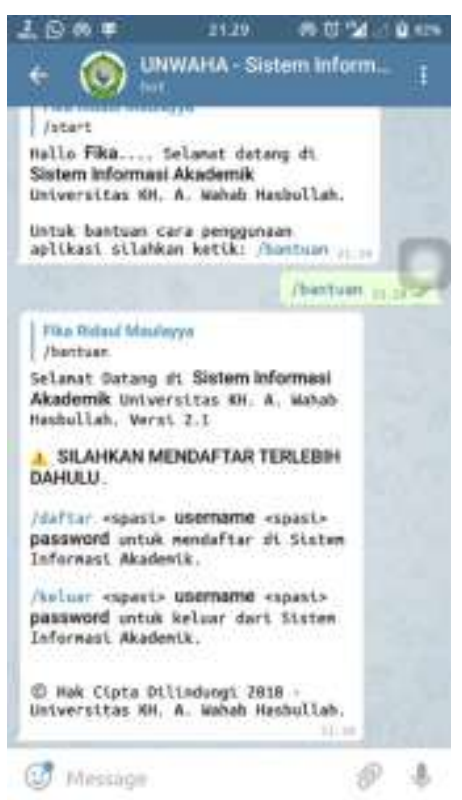

Gambar 7. Tampilan Daftar Menu Aplikasi BOT Telegram

3. Tampilan Menu Daftar

Perintah daftar adalah perintah yang digunakan user untuk mendaftar di sistem, dengan cara memasukkan username/nim dan password, sesuai dengan data di sistem informasi akademik.

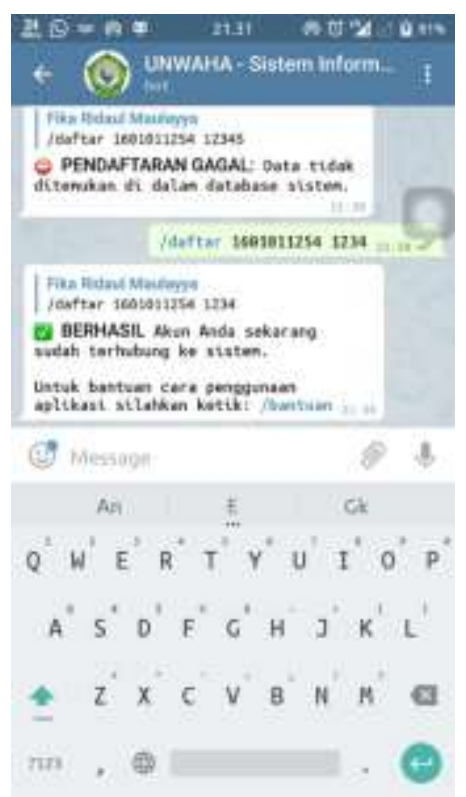

Gambar 8. Tampilan Daftar Aplikasi BOT Telegram

4. Tampilan Menu Aplikasi

Perintah bantuan setelah mendaftar adalah perintah yang akan menampilkan menu-menu yang ada di aplikasi, dengan cara user harus mendaftar terlebih dahulu. 


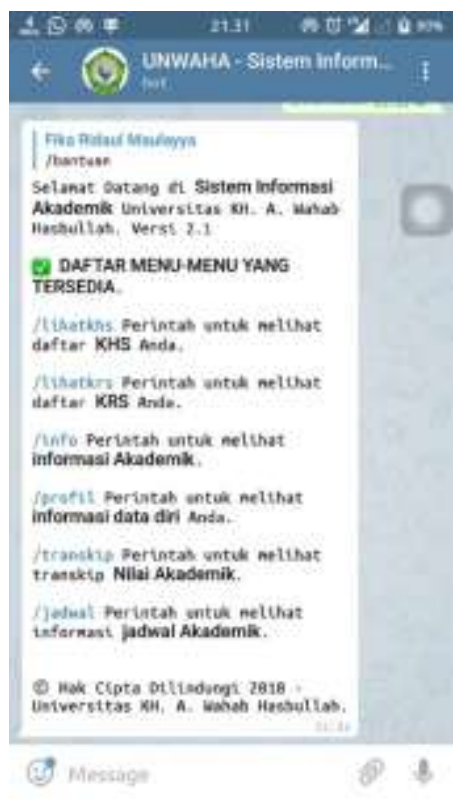

Gambar 9. Tampilan Daftar Menu BOT Telegram

\subsection{Tabel Pengujian}

Setelah dilakukan Uji Fungsi pada aplikasi BOT Telegram didapatkan data yang menunjukan hubungan penggunaan waktu request antara sistem informasi akademik versi BOT dan website. Perbandingan bias dilihat pada Tabel dibawah ini:

Tabel 2. Perbandingan Bandwidth $512 \mathrm{~Kb}$

\begin{tabular}{|c|c|c|c|c|}
\hline No. & Jenis Request & Bandwidth & BOT & Website \\
\hline 1. & Halaman Awal & $10.16 \mathrm{Mbps}$ & $2.41 \mathrm{~s}$ & $2.49 \mathrm{~s}$ \\
\hline 2. & Halaman Profil & $10.16 \mathrm{Mbps}$ & $2.94 \mathrm{~s}$ & $3.26 \mathrm{~s}$ \\
\hline 3. & Halaman Jadwal & $10.16 \mathrm{Mbps}$ & $2.57 \mathrm{~s}$ & $3.19 \mathrm{~s}$ \\
\hline 4. & Halaman Info & $10.16 \mathrm{Mbps}$ & $2.41 \mathrm{~s}$ & $3.12 \mathrm{~s}$ \\
\hline 5. & Halaman Transkip & $10.16 \mathrm{Mbps}$ & $2.08 \mathrm{~s}$ & $3.34 \mathrm{~s}$ \\
\hline 6. & Halaman Detail KHS & $10.16 \mathrm{Mbps}$ & $2.52 \mathrm{~s}$ & $3.01 \mathrm{~s}$ \\
\hline 7. & Halaman Cetak KHS & $10.16 \mathrm{Mbps}$ & $2.37 \mathrm{~s}$ & $3.33 \mathrm{~s}$ \\
\hline 8. & Halaman Detail KRS & $10.16 \mathrm{Mbps}$ & $2.24 \mathrm{~s}$ & $3.32 \mathrm{~s}$ \\
\hline 9. & Halaman Cetak KRS & $10.16 \mathrm{Mbps}$ & $2.49 \mathrm{~s}$ & $3.37 \mathrm{~s}$ \\
\hline
\end{tabular}

Tabel 3. Perbandingan Bandwidth $1 \mathrm{MB}$

\begin{tabular}{|c|c|c|c|c|}
\hline No. & Jenis Request & Bandwidth & BOT & Website \\
\hline 1. & Halaman Awal & $4.51 \mathrm{Mbps}$ & $3.35 \mathrm{~s}$ & $7.76 \mathrm{~s}$ \\
\hline 2. & Halaman Profil & $4.51 \mathrm{Mbps}$ & $2.02 \mathrm{~s}$ & $8.18 \mathrm{~s}$ \\
\hline 3. & Halaman Jadwal & $4.51 \mathrm{Mbps}$ & $3.11 \mathrm{~s}$ & $3.71 \mathrm{~s}$ \\
\hline 4. & Halaman Info & $4.51 \mathrm{Mbps}$ & $3.75 \mathrm{~s}$ & $4.16 \mathrm{~s}$ \\
\hline 5. & Halaman Transkip & $4.51 \mathrm{Mbps}$ & $2.96 \mathrm{~s}$ & $4.44 \mathrm{~s}$ \\
\hline 6. & Halaman Detail KHS & $4.51 \mathrm{Mbps}$ & $2.01 \mathrm{~s}$ & $3.12 \mathrm{~s}$ \\
\hline 7. & Halaman Cetak KHS & $4.51 \mathrm{Mbps}$ & $3.73 \mathrm{~s}$ & $6.93 \mathrm{~s}$ \\
\hline 8. & Halaman Detail KRS & $4.51 \mathrm{Mbps}$ & $3.08 \mathrm{~s}$ & $3.86 \mathrm{~s}$ \\
\hline 9. & Halaman Cetak KRS & $4.51 \mathrm{Mbps}$ & $2.86 \mathrm{~s}$ & $6.89 \mathrm{~s}$ \\
\hline
\end{tabular}




\subsection{Grafik Pengujian}

Setelah dilakukan Uji Fungsi pada aplikasi BOT Telegram didapatkan data yang menunjukan hubungan penggunaan waktu request antara sistem informasi akademik versi BOT dan website. Perbandingan bias dilihat pada Gambar grafik dibawah ini:

GRAFIK PERBANDINGAN BANDWIDTH 512 Kb

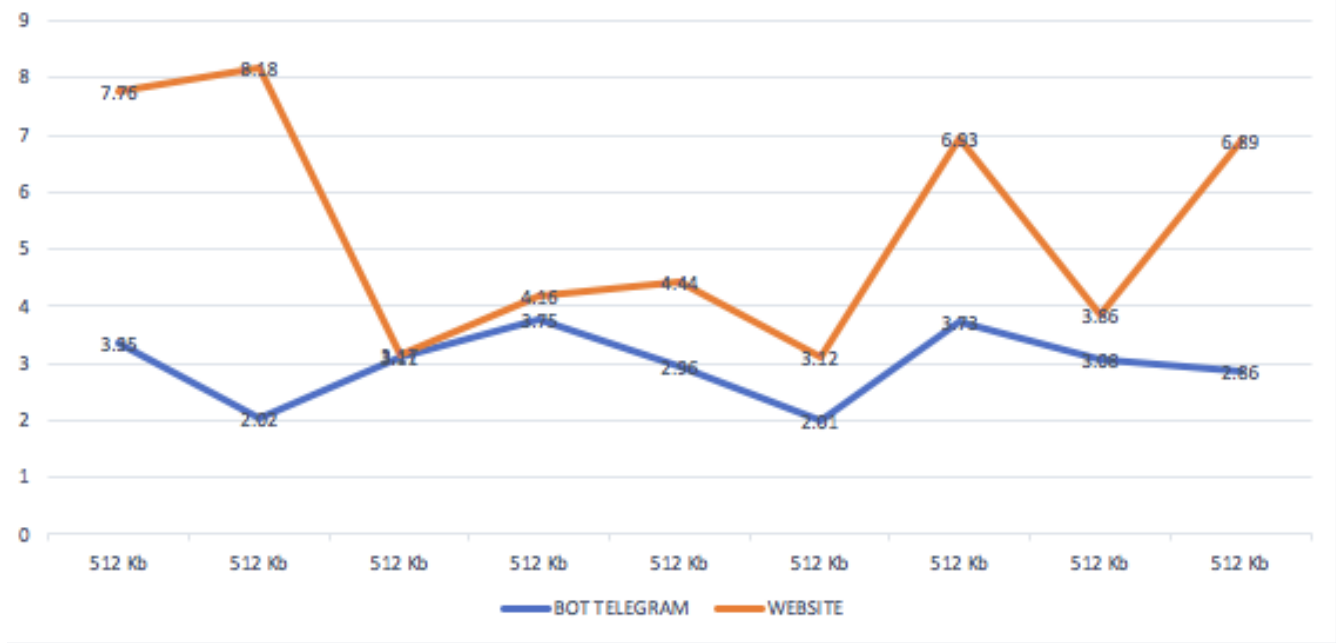

Gambar 10. Grafik Perbandingan Bandwidth $512 \mathrm{~Kb}$

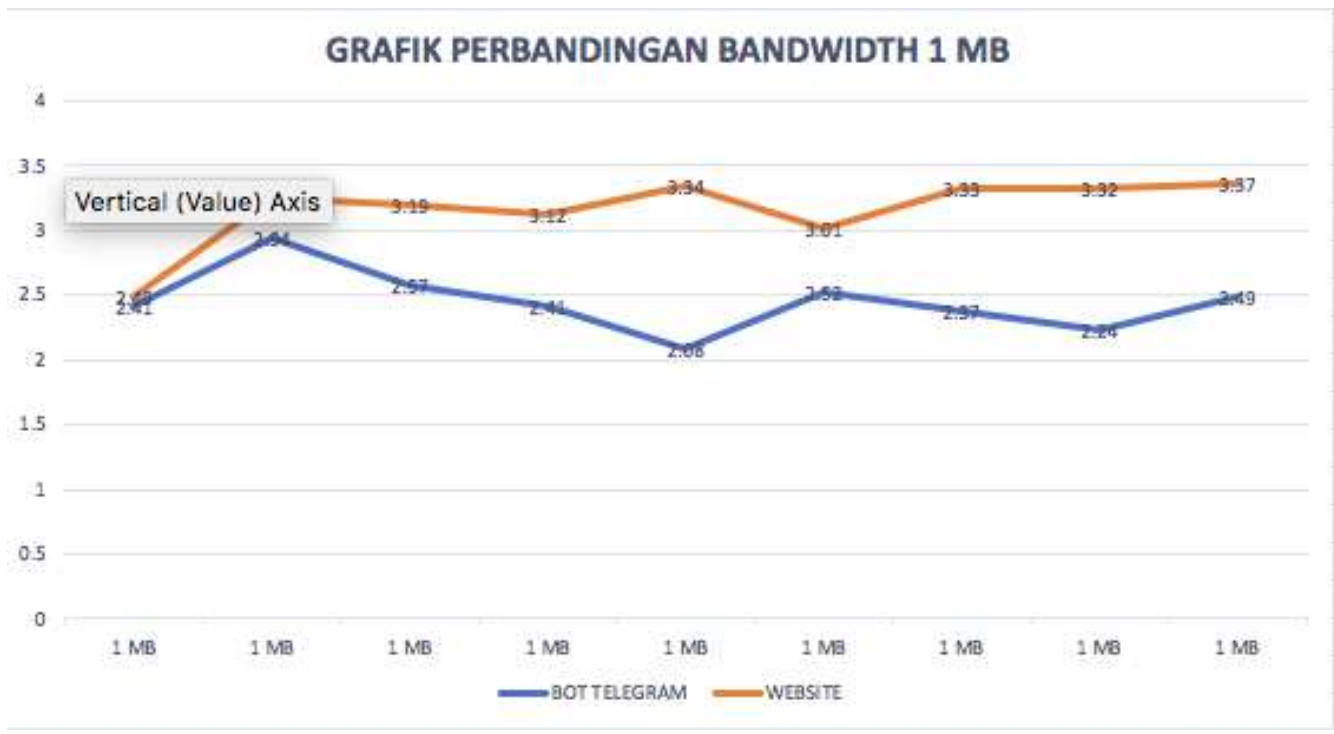

Gambar 11. Grafik Perbandingan Bandwidth $1 \mathrm{MB}$

\section{KESIMPULAN}

Berdasarkan hasil pengumpulan dan analisis data serta proses pembuatan aplikasi, maka dapat diambil kesimpulan sebagai berikut:

1. Memanfaatkan pesan instan sebagai alternatif yang efisien untuk mempermudah mahasiswa dalam mendapatkan infromasi seputar akademik dimana dan kapan saja.

2. Dengan menggunakan aplikasi sistem informasi berbasis BOT Telegram, mahasiswa dapat lebih mudah dan cepat didalam mendapatkan informasi akademik.

3. Dengan menerapkan sistem chat id sebagai autentikasi di sistem informasi akademik berbasis BOT Telegram untuk menjaga informasi data akademik yang aman. 


\section{DAFTAR PUSTAKA}

Cokrojoyo, Anggiat., Andjarwirawan, Justinus., Noertjahyana , Agustinus. 2016. Pembuatan Bot Telegram Untuk Mengambil Informasi dan Jadwal Film Menggunakan PHP. Surabaya: Universitas Kristen Petra.

Dewi Risanti Rita., Sopiyan Ade. 2017. Pembuatan Aplikasi Kuesioner Evaluasi Belajar Mengajar Menggunakan Bot Telegram Pada Fakultas Teknik Universitas Muhammadiyah Jakarta (FtUmj) Dengan Metode Polling. Jakarta: Seminar nasional Sains dan Teknologi. (p-ISSN : 2407 - 1846, e-ISSN : 2460 - 8416).

Ericsson, Loreto., Cisco, Saint-Andre. 2013. Known Issues and Best Practices for the Use of Long Polling and Streaming in Bidirectional HTTP. Italy : Internet Engineering Task Force (IETF). (ISSN: 2070-1721).

Hartati, Sri. 2015. Analisis Perancangan E-Commerce Pada Wisaelektronik Kemiling Bandar Lampung. Lampung: STMIK Pringsewu Lampung.

Nur Rochim, Hatta. 2016. Rancang Bangun Telegram Bot Pada Telegram Messenger Dengan Metode Long Polling Untuk Koperasi Kopma Ugm. Yogyakarta : Universitas Gadjah Mada.

Murthy, Rao., S.Tejeswara., Rao, G.Mohana. 2017. Home Automation using Telegram. India : MVGR College of Engineering. Vol. 6, Issue 6, June 2017.

Parawangsa, Rifqi Dwiputra. 2016. Rancang Bangun Prototype Smart Home Menggunakan Telegram Messenger Berbasis Arduino Uno. Jakarta : Universitas Mercu Buana.

Rachman Dhenny., Noor Al Azam Moh., Anindito Benediktus. 2017. Sistem Pemantau \& Pengendalian Rumah Cerdasmenggunakan Infrastuktur Internet Messaging. Surabaya: Universitas Narotama Surabaya. Vol.26, No. 1 (ISSN 1858 - 4667).

Utomo Dias., Sholeh Muchammad., Avorizano. 2017. Membangun Sistem Mobile Monitoring KeamananWeb Aplikasi Menggunakan Suricata dan BotTelegram Channel. Jakarta: Seminar Nasional TEKNOKA. Vol. 2, No. 1 (ISSN 2502 - 8782).

Vatsa, Vedang Ratan., Singh, Gopal. 2016. Raspberry Pi based Implementation of Internet of ThingsusingMobile Messaging Application -'Telegram'. India : M.D. University. Volume 145 -No.14.

Zennaro, Marco., Pietrosemoli, Ermanno., Marco, Rainone. 2017. Radio Link Planning made easywith a Telegram Bot. Italy : ICTP Telecommunication/ICT4D Lab. (ISSN 1867-821). 